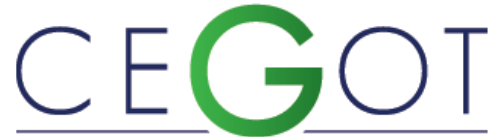

Centro de Estudos de Geografia e Ordenamento do Território

\author{
AMARAL BRITO, MÁRCIO \\ Universidade Federal do Pará (UFPA) \\ Instituto de Tecnologia - R. Augusto Corrêa, 01 - Guamá, Belém - PA, 66075-110, Brazil \\ marcioamaral29@gmail.com \\ BARBOSA SILVA, LUIZ \\ Universidade Federal do Pará (UFPA) \\ Instituto de Tecnologia - R. Augusto Corrêa, 01 - Guamá, Belém - PA, 66075-110, Brazil \\ luizmarcelo_sb@hotmail.com
}

Silva AzeVedo, Felipe

Universidade Federal do Pará (UFPA)

Instituto de Tecnologia - R. Augusto Corrêa, 01 - Guamá, Belém - PA, 66075-110, Brazil

giordano-silva@hotmail.com

\title{
O urbano no Salgado Paraense: a pequena cidade de Marapanim nas redes da pesca
}

The urban in Salgado, a Pará state region: the Marapanim small town in the nets of fishing

Referência: Amaral Brito, M.; Barbosa Silva; L.; Silva Azevedo, F. (2020). O urbano no Salgado Paraense: a pequena cidade de Marapanim nas redes da pesca. Revista de Geografia e Ordenamento do Território (GOT), no 19 (junho). Centro de Estudos de Geografia e Ordenamento do Território, p. 29-56, dx.doi.org/10.17127/got/2020.19.002

\section{RESUMO}

O presente trabalho tem como objetivo central analisar a economia política da cidade de Marapanim (PA), localizada na Microrregião do Salgado, em face da sua participação na divisão territorial do trabalho relacionada à atividade pesqueira. Para tanto, foram realizados levantamentos bibliográficos, análise de documentos da colônia de pescadores, da Prefeitura Municipal e do IBGE, que tratam do registro da economia pesqueira, entrevistas semiestruturadas gravadas com os agentes envolvidos, e mapeamento acerca dos espaços de produção, circulação e distribuição de peixe. Esse estudo levou a entender que a cidade de Marapanim participa da divisão territorial do trabalho como um "espaço de suporte" à produção, à comercialização, ao consumo e ao controle/fisco da economia pesqueira regional de natureza artesanal.

Palavras-chave: Marapanim; Economia política da cidade; Pequenas cidades; Pesca.

\section{ABSTRACT}

The present paper has as it's main objective an analyses of Marapanim's city political economy, located in Pará's state Salgado micro region, in face of it's participation in the territorial's labor division related to the fishing activity. In order to do so, we have carried 
out bibliographical researches, analysis of documents, records of the fishing economy produced by the fishermen's colony, the Municipal Government and the Geographical and Statistic Brazilian Institute (IBGE); it also employed semi-structured interviews, recorded with involved agents; and the space mapping of the fish production, circulation and distribution. This research led us to understand that Marapanim's city participates at the territorial's labor division as a space that "supports" production, marketing, consumption and the control/fiscal of the regional's artisanal fishing economy.

Keywords: Marapanim; City Political Economy; Small Towns; Fishing.

\section{Introdução}

O presente trabalho aborda a inserção de uma pequena cidade da Amazônia paraense, Marapanim, na divisão territorial do trabalho, bem como as implicações dessa participação na sua organização intraurbana. Trata-se de sustentar que Marapanim está envolvida numa economia pesqueira artesanal, cujo funcionamento estrutura o espaço da cidade e, ao mesmo tempo, permite a existência de uma produção do espaço pautada em um acontecer solidário.

Embora existam pesquisas que ressaltem a necessidade de discutir a diversidade territorial e urbana da Amazônia (Trindade Jr. 2010 e Oliveira; Schor, 2011), principalmente da porção regional dinamizada pelos grandes rios, nenhuma delas se preocupou ainda em investigar a particularidade do litoral de rias paraense ${ }^{1}$, uma região de colonização antiga da Amazônia, cuja dinâmica econômica está pautada em uma economia pesqueira e em fortes interações espaciais entre a terra, os rios e o mar.

Para a realização da pesquisa adotou-se como método a proposta de Santos (2009) a respeito da economia política da urbanização e da economia política da cidade, em que se buscou de um lado, verificar como concretamente a cidade de Marapanim participa da divisão territorial do trabalho pesqueiro artesanal ${ }^{2}$ realizado na sua região de influência e, de outro lado, apontar como essa participação faz com que a cidade se organize

1 "Originada de uma imersão do litoral com a consequente invasão do mar nos vales modelados pela erosão fluvial. As costas deste tipo são altas e os rios afogados e de larga embocadura. A ria é, portanto, um tipo de costa de submersão, caracterizada por apresentar vales muito largos com foz em forma de trombeta" (Guerra; Guerra, 2008, 543).

2 Embora a pesca encontrada no município de Marapanim realize a captura de crustáceos (tais como caranguejo, camarão-rosa e siri) e moluscos (como o sarnambi), este artigo foca no extrativismo de peixes, sem deixar de considerar os demais produtos coletados pelos pescadores (Borcem et al., 2011). 
internamente para atender aos ditames da produção, da circulação e do consumo de pescado.

Como procedimentos metodológicos foram efetivados um levantamento e análise bibliográfica relativos às pequenas cidades na Amazônia, além da formação socioespacial e das atividades pesqueiras na microrregião do Salgado, em especial, da cidade de Marapanim; acrescentou-se levantamento e análise documental de dados secundários obtidos no Instituto Brasileiro de Geografia e Estatística (IBGE), na Prefeitura Municipal de Marapanim, no Mercado Municipal e na Colônia dos Pescadores Z-6; concretizou-se ainda trabalhos de campo, com observação sistemática da realidade e realização de entrevistas semiestruturadas aos pescadores, com os marreteiros e com os atravessadores ${ }^{3}$; também foram entrevistados os comerciantes de materiais para pesca, os representantes da Secretaria de Pesca da Prefeitura, o presidente da Colônia dos Pescadores Z-6 e o diretor do Mercado Municipal. Por fim, mapearam-se os espaços da cidade que participam do circuito espacial da produção pesqueira.

A primeira parte do texto discute as perspectivas teóricas que orientaram esta pesquisa, enfatizando a relação entre a divisão territorial do trabalho e as pequenas cidades. A segunda parte compreende a formação socioespacial de Marapanim, destacando a sua participação na economia pesqueira regional. A terceira parte analisa a participação de Marapanim na divisão do trabalho por meio da atividade da pesca, bem como sua organização interna em face dessa participação. Por fim, apontam-se algumas considerações no sentido de avançar no entendimento da diversidade urbana da Amazônia, propondo novas possibilidades para se pensar as pequenas cidades litorâneas e sua vida de relações.

\section{As pequenas cidades e a divisão territorial do trabalho}

Em recente pesquisa sobre o tratamento dado às pequenas e médias cidades nos estudos urbanos contemporâneos, Demazière (2017) aponta que essas cidades estão colocadas

\footnotetext{
${ }^{3} \mathrm{O}$ atravessador é uma agente que compra diretamente dos pescadores e/ou dos aviadores para depois vender o pescado aos comerciantes varejistas ou pode ser um intermediário que transporta e vende o pescado em outros municípios e estados do país, tendo uma relação comercial de alcance local, regional e nacional. Já os marreteiros acumulam pequenas quantidades de pescado, obtidas diretamente de vários pescadores, e as vendem nas vilas e na sede municipal para feirantes, comerciantes e, mesmo, atravessadores, resultando num alcance de ação restrito (Santos et al., 2005).
} 
como um objeto de pesquisa à margem. Os trabalhos relativos à compreensão da cidade em face da mundialização, claramente privilegiam as metrópoles em detrimento das demais frações urbanas. As perspectivas teóricas têm contribuído, significativamente, para tornar "invisíveis" os espaços urbanos não metropolizados, algo que está relacionado com o papel funcional desempenhado pelas metrópoles diante do desenvolvimento econômico.

A realidade brasileira não é muito diferente, como destacou Sposito (2004), pois os estudos que têm se dedicado ao entendimento da relação entre a economia globalizada e a urbanização procuram enfatizar a importância das grandes metrópoles do país, numa articulação direta entre global e local. Contrariamente a esse tipo de leitura, o funcionamento em rede da economia tem permitido que cidades que não desempenham papel de "cidades globais", possam participar de circuitos e de interações que não são comandadas por hierarquias urbanas.

Para Ribeiro (2006), é a inserção dos países numa nova divisão territorial do trabalho, face à globalização, o que tem desafiado as pesquisas urbanas, fortemente aprisionadas nos espaços metropolitanos, para uma reflexão crítica, uma vez que o conteúdo do território tem sido alterado. Como ressalta, historicamente houve no Brasil uma extraordinária concentração de recursos, de população e mesmo de centros de pesquisa nas metrópoles que, em certo sentido, justificava a centralidade dos estudos de natureza metropolitana, mas, na atualidade, uma leitura mais íntegra da urbanização brasileira não deve prescindir de constatar que houve, ora uma descentralização político-administrativa no país, derivada do processo de democratização da sociedade, ora uma desconcentração da dinâmica econômica observada nas transformações da relação campo-cidade e nos imperativos da produção capitalista.

Diante dessas considerações que desafiam as pesquisas urbanas a pensar na totalidade da organização do território sem privilegiar apenas uma das suas dimensões - a metropolitana - em detrimento das demais - as cidades pequenas e médias - é que se coloca, na presente pesquisa, o entendimento das pequenas cidades. Ressalta-se, contudo, que a opção teóricometodológica adotada para isso, muito embora se reconheça a existência de outras, é a proposta por Santos (2009) a respeito da economia política da urbanização e da economia política da cidade. 
Se de um lado, a economia política da urbanização parte da divisão social do trabalho que produz uma divisão territorial do trabalho ${ }^{4}$, de outro lado, a economia política da cidade investiga a forma como a cidade se organiza internamente em face da produção, bem como a forma como os atores da vida urbana encontram os seus lugares dentro da cidade.

Acrescente-se a isso o entendimento de que, além da divisão do trabalho hegemônica sustentada na ação dos grandes agentes econômicos, existe outra divisão do trabalho pautada no "reino da práxis", nas horizontalidades e nas solidariedades orgânicas e não organizacionais (Silveira, 2011).

Diante disso, torna-se necessário, ainda, aprofundar um pouco mais a discussão sobre as pequenas cidades, relacionada à divisão territorial do trabalho e a rede urbana. Neste sentido, ao interpretar as contribuições de Santos (1979), Damiani (2006) afirma que existem duas leituras a respeito da classificação das cidades dentro da rede urbana: uma que se satisfaz com o "dado demográfico bruto" e que faz a sua classificação segundo o volume populacional (cidades pequenas, médias, grandes e muito grandes), outra que se preocupa em fazer uma classificação de natureza funcional, considerando a cidade como industrial, comercial, administrativa etc. Diante dessas duas formas de classificar a cidade, a autora mostra que Santos (1979) acabou optando por fazer uma classificação tendo em vista a capacidade de organização do espaço pela cidade, assim, ter-se-ia as cidades locais, as cidades regionais, as metrópoles incompletas e as metrópoles completas.

A respeito das cidades locais, Santos (2005) mostra que a adoção desse termo é mais interessante do que aquele que é amplamente utilizado pela literatura especializada, cidades pequenas, pois permite uma abordagem mais funcional do fenômeno urbano, num âmbito mais qualitativo e com aspectos morfológicos específicos de cada civilização. Ele chega mesmo a considerá-las como "cidades de subsistência", uma vez que possuem apenas uma dimensão mínima de aglomeração urbana, uma função de primeiro nível hierárquico, que lhes permite atender às "necessidades vitais mínimas, reais ou criadas de toda uma população" (Santos, 2005, 71), o que nos permite constatar uma especialização do espaço.

\footnotetext{
${ }^{4}$ Apontando a distribuição dos instrumentos de trabalho, do emprego e dos homens na superfície da terra, auxiliando a estabelecer a relação da cidade com a região, ou mesmo da metrópole com a região.
} 
Enquanto as metrópoles têm a sua existência relacionada com os novos modelos de produção fundados na lógica da concentração, as cidades locais têm sua trajetória relacionada com as transformações no modelo de consumo sob a égide da modernização tecnológica e fundada na lógica da dispersão, cujo comando é dado "pela difusão generalizada da informação e do consumo" (Santos, 2005, 91). Nas áreas de produção primárias, as cidades locais funcionam no sentido de permitir o acesso da população a um consumo mais próximo daquele realizado em outras áreas mais modernas do país, enquanto garante a expansão da economia urbana.

Ao estudar esse tipo de cidade, embora preferindo utilizar o termo cidades pequenas, Sposito (2009) fez uma série de recomendações necessárias ao seu estudo. Um dos pontos diz respeito às suas articulações, considerando que, sendo diferente da metrópole, as pequenas cidades não são entidades autônomas e dotadas de nível significativo de complexidade. Desse modo, dentre as articulações apontadas de Sposito (2009) para o estudo das pequenas cidades, pode-se destacar os seguintes pares: a relação entre rural e urbano, que exige pensar os espaços municipais que estão sob o seu comando; a relação cidade e natureza; a relação entre cidade e região, desde que se considerem as mudanças nesse conceito de região; a relação entre continuidade e descontinuidade; a relação entre concentração e dispersão (ou entre densidade e extensão) e, por fim, a relação entre polarização e difusão.

Sposito e Jurado (2013), por sua vez, afirmam que no Brasil a produção geográfica sobre as cidades pequenas ainda é pouco expressiva, uma vez que as pesquisas sobre os espaços urbanos se direcionam, geralmente, para as cidades grandes e médias. Para eles, a cidade pequena não deve ser vista como um dado a priori e "em si", portanto, não deve ser interpretada de maneira isolada, mas no conjunto das relações que estabelece com outros centros urbanos. Apesar de apresentarem particularidades, a análise das pequenas cidades, no plano teórico, deve estar coesa a processos mais amplos, envolvendo uma discussão da rede urbana. Segundo eles:

Trata-se de uma construção social e coletiva, além de uma elaboração teórica e prática de membros da comunidade científica, a qual produz reflexões analíticas, algo consensual e/ou reconhecido/negado para a compreensão do urbano e da estruturação da sociedade (Sposito e Jurado, 2013, p.17). 
No mesmo sentido, destacou Endlich (2009), referindo que o estudo sobre pequenas (e médias) cidades não pode prescindir do "entorno regional", pois é ele que permite verificar o alcance dos papéis urbanos e das dinâmicas regionais que lhe servem de sustentação. Do mesmo modo, não se deve desprezar as comparações, cujo objetivo central é verificar as dimensões variáveis do fenômeno urbano, uma vez que uma dimensão que caracteriza determinada cidade como pequena em uma região, pode não servir para outra.

Ao refletir sobre as pequenas cidades na Amazônia é necessário recuperar o debate sobre a diversidade territorial e urbana na Amazônia, já que, segundo Trindade Jr. (2010), não tem sido objeto de investigações, pois os estudos sobre a região estão muito mais centrados em uma preocupação com a análise da biodiversidade e/ou da sociodiversidade regional.

Ao destacar a necessidade de se construir uma reflexão sobre a urbano-diversidade regional, Trindade Jr. (2010) destaca que é preciso fazer um trabalho no plano teórico, no sentido de entender que a urbanização se manifesta de forma diferenciada no território. Inclusive, reforça a existência de diversos tipos de cidades e múltiplas formas de urbanização, enquanto no plano da ação política, realça a necessidade de pensar políticas urbanas mais plurais, associadas a uma legislação que seja capaz de incorporar a diversidade e a pluralidade dos conteúdos urbanos do país.

Procurando aprofundar a discussão sobre pequenas cidades a partir da realidade amazônica, Trindade Jr. (2013) propõe o par dialético: "cidade da floresta" e "cidades na floresta".

As "cidades $\boldsymbol{d a}$ floresta" referem-se as aglomerações que dominaram a cena amazônica até a década de 1960, apresentando-se como pequenas e associadas à circulação fluvial, bem como tendo fortes interações espaciais com a natureza, com a vida rural não moderna, com a floresta ainda pouco explorada e com seus entornos imediatos e cidades próximas. Exemplos desse tipo de cidade são as chamadas "cidades ribeirinhas", as de "colonização agrária antiga" e as "cidades híbridas".

As "cidades na floresta", por outro lado, referem-se àquelas cidades instaladas na região e que, em face do processo de modernização regional, apresentam forte articulação com demandas externas. Dessa forma, deixa a floresta de fora da integração da sociedade e dos novos valores da vida urbana, produzindo-a principalmente, como espaço de exploração 
econômica. Dentre os exemplos, destacam-se as "cidades-empresa" e as "cidades rodoviárias".

Em estudo sobre as articulações entre as cidades da Calha dos Rios Solimões-Amazonas, com o objetivo de construir uma tipologia da rede urbana nela presente, Oliveira (2009) acaba por apontar elementos da urbano-diversidade para a porção mais ocidental da Amazônia brasileira, muito embora não utilize dessa expressão. O autor destaca a existência de um conjunto de lugares que se relacionam diretamente com o mundo, numa lógica da mundialização, da relação local-global e, por outro lado, destaca a existência de lugares cujas histórias e trajetórias estão relacionadas à preservação de outro modo de vida, cidades que não foram extremamente afetadas pela mundialização e que podem servir de reserva territorial estratégica para a construção de um novo modo de vida (Oliveira, 2009). Neste sentido, fazendo uso de variáveis que expressam a funcionalidade e a capacidade de conexão das cidades da Calha do Solimões-Amazonas entre si, com as demais cidades localizadas fora dela, propõe a seguinte tipologia e hierarquia urbana das cidades pequenas: Cidade Pequena de Responsabilidade Social, Cidade Pequena com Dinâmica Econômica Externa, Cidade Pequena de Fronteira e Cidades Pequenas Dependentes (Oliveira, 2009).

Por mais que se reconheça o esforço dos dois últimos autores em refletir sobre a diversidade territorial e urbana da Amazônia, não se pode deixar de destacar que a realidade do litoral paraense (da microrregião do Salgado) ficou excluída das suas preocupações. Não é preocupação desse trabalho investigar as razões dessa ausência, mas tão somente acrescentar elementos históricos e empíricos que justifiquem a ampliação dessas classificações de modo a incorporar uma porção territorial da região que tem ficado excluída das pesquisas acadêmicas mais recentes, pelo menos no âmbito da Geografia Urbana, principalmente por acreditar que ela apresenta particularidades e singularidades que precisam ser reveladas para ampliar o entendimento da realidade geográfica amazônica e para que sejam melhor integradas às políticas públicas.

\section{A formação socioespacial da pequena cidade de Marapanim: entre a farinha e o peixe}

O objetivo deste tópico é analisar a formação socioespacial do litoral paraense e de Marapanim. Para isso, optou-se em trabalhar com a categoria da formação socioespacial 
que, de acordo com Santos (2005), procura superar o debate geográfico centrado apenas na forma das coisas para compreender, geograficamente, por meio de sua formação, um tipo de investigação que considera as dinâmicas sociais que produzem e transformam as formas, via processos históricos de espacialização.

De acordo com Santos $(2005,22)$ trata-se de inserir o espaço no debate da formação econômica e social, pois se refere à "evolução diferencial das sociedades no seu quadro próprio e em relação com as forças externas", estando sua explicação focada na produção, no trabalho humano que transforma o espaço de acordo com as leis determinadas historicamente. Segundo esse autor, é preciso tratar as formações socioeconômicas, distinguindo-a da formação socioespacial, pois no Brasil há uma formação socioeconômica capitalista e dentro dele existem diferentes formações socioespaciais, como a da própria Amazônia, por exemplo. O Espaço, na perspectiva metodológica de Santos $(2005,31)$, não deve ser visto como uma "simples tela de fundo inerte e neutro", de modo que o processo histórico não pode se realizar senão no espaço e pelo espaço, estando, portanto, a evolução da formação social condicionada pela espacialidade, entendida tanto em termos de heranças (diacrônico), quanto em termos atuais (sincrônico).

Para fazer uma breve discussão acerca da formação socioespacial do litoral paraense e de Marapanim parte-se, inicialmente, das contribuições de Égler (1961) quando afirma que existiam três caminhos principais para alcançar São Luís do Maranhão, sede administrativa e base do abastecimento da então província do Grão-Pará: plo litoral, que deu origem a um conjunto de pequenos núcleos utilizados como base logística para a navegação entre Belém e São Luís; pelo Rio Guamá, em que se navega de Belém até a altura de Ourém (PA), passando pelo núcleo de São Miguel do Guamá (Pará), e daí, por via terrestre, até às cabeceiras do Rio Caeté, para então chegar até Bragança, por trilhas de índios e, de lá, até São Luís do Maranhão, viajando ao longo da costa. Já o terceiro caminho era uma precária estrada para Bragança, que ficava localizada numa extensa área de mata entre o litoral e o Rio Guamá, que era utilizada para transporte de gado, e onde hoje estão localizados os núcleos urbanos de Castanhal, Igarapé-Açu, Timboteua e Capanema (Égler, 1961).

Pelos objetivos desta pesquisa destaca-se a área do Salgado cujo processo de ocupação está relacionado, como já dito, com as interações espaciais existentes entre Belém e São Luís através da circulação marítima. Por meio de uma viagem perigosa, realizada em pequenas 
embarcações à vela que precisavam aportar constantemente em busca de proteção e reabastecimento, o que acabou por produzir um "verdadeiro rosário de pequenos núcleos de povoamento ao longo da costa do Pará" (Égler, 1961, 528). A título de exemplo, entre Belém e Bragança cidades pequenas, tais como: Vigia, São Caetano de Odivelas, Curuçá, Marapanim, Maracanã, Salinas, São João de Pirabas, São João da Ponta e Quatipuru.

Na realidade, antes da colonização europeia na Amazônia, a presença humana no litoral paraense já era milenar, havendo registros de povos pescadores-coletores que datam de, aproximadamente, 3 mil anos, sendo que muitos dos hábitos desses povos antigos estão presentes na cultura das comunidades pesqueiras do litoral do Pará e Amapá (Furtado, 1987). Assim, a Amazônia já era habitada por populações antes da chegada dos europeus, derrubando uma ideia, renovada em certos momentos, de um vazio demográfico na região (Gonçalves, 2015).

Dentre as populações que já existiam antes da colonização europeia, destaca-se a grande família dos Tupinambá, que estava presente no Norte do país, e da qual faziam parte os indígenas Pacajás, que habitavam o que hoje é o município de Marapanim (Furtado, 1987). Com a chegada do Padre João do Souto Maior, por volta de 1656, os índios Pacajá foram aldeados, dando origem, então, a uma aldeia missionária em Arapijó, na margem do Rio Marapanim, por ordem da Companhia de Jesus (Castro, 1998) que estava assentada numa fazenda chamada "Bom Intento", conforme aponta Furtado (1987).

Ressalta-se que até meados do século XVIII, o cenário era de pouco dinamismo econômico nas aldeias, limitando-se principalmente à exploração das drogas do sertão. No Salgado, as principais atividades eram a agricultura e a pesca e os habitantes revezavam tais atividades segundo as safras (Furtado, 1987 e Loureiro, 1983).

A exploração dos recursos nas aldeias era feita pela mão de obra indígena, sob o controle das ordens religiosas, e os recursos eram escoados até Belém e de lá para Portugal, beneficiando as ordens religiosas em detrimento da burguesia, do Estado português e dos grupos comerciais ingleses que, por acordos comerciais com Portugal, buscavam controlar seu comércio ultramarino (Corrêa, 2006).

A chegada de Mendonça Furtado (Governador Geral e irmão do Marquês de Pombal) à Amazônia, em 1751, coincide com a transformação do Estado do Maranhão e Grão-Pará em Estado do Grão-Pará e Maranhão, juntamente com a mudança da sede da administração 
colonial de São Luís para Belém. Dentre os principais problemas do período Pombalino, mesmo depois da expulsão dos jesuítas da Amazônia, Almeida (2008) destaca o "modelo de colonização de base teológica", que além de edificações e de relatos sobre a devastação e o massacre de indígenas por sesmeiros e colonos, implantou formas particulares de religiosidade e de poder na sociedade colonial.

Almeida (2008) afirma que a Religião e a Teologia foram os principais alvos do "pensamento ilustrado" de Pombal, que, com a sua formação iluminista, redefiniu o projeto colonial, destacando o papel do Estado e menosprezando a ação confessional, principalmente no domínio econômico. Assim, ao contrário do dogma religioso, Pombal escolheu o saber científico e o gerenciamento econômico como forma de subordinar os empreendimentos das ordens religiosas às políticas do Estado. Nesse contexto, por meio de "medidas racionalburocráticas", delineou-se os traços distintivos do Estado Moderno (do Estado-Nação) em oposição ao Estado dinástico dos religiosos, incorporando permanentemente a natureza aos empreendimentos da agricultura tropical.

O resultado concreto dessa política para a microrregião do Salgado não foi positivo, ao contrário de outras áreas da Amazônia, em que se verificou uma maior dinamização econômica em função da introdução da agricultura comercial, da pecuária e do trabalho escravo negro. No Salgado, segundo Baena (1885), houve uma desorganização da estruturação socioespacial, cujo epicentro irradiavam das ordens religiosas.

O segundo grande momento da formação socioespacial da microrregião do Salgado, e que vai ter implicações diretas na formação de Marapanim, está relacionado com o início da ocupação planejada da região, num contexto de expansão do extrativismo da borracha (1850-1920) na Amazônia. Esse período foi responsável por diferentes transformações na região, especialmente nas capitais, Manaus e Belém; de acordo com Corrêa (2006), o látex extraído das seringueiras, existente em grande abundância no interior da floresta e valorizado pelo mercado internacional como matéria-prima para a indústria de pneumáticos, insere a região amazônica na Divisão Internacional do Trabalho.

É importante ressaltar que se, por um lado o boom da borracha trouxe grandes transformações político-econômicas e no modo de vida da região, por outro lado, não se pode esquecer que ela também promoveu o declínio da atividade agrícola, o que acabou por provocar uma crise de abastecimento em Belém, por exemplo, bem como um conflito 
de ordem política entre a oligarquia latifundiária tradicional e o setor extrativista da borracha. A forma encontrada para solucionar esses problemas foi a política de colonização da região bragantina (ocorrida entre as últimas décadas do séc. XIX até à primeira década do séc. $X X)$, realizada ao longo da Estrada de Ferro de Bragança (EFB), através da criação de numerosas colônias agrícolas, cujas sedes transformaram-se em núcleos urbanos naquela mesorregião. Inicialmente, faziam uso da mão de obra europeia (especialmente portugueses, franceses e espanhóis), e, posteriormente, com maior êxito, utilizaram mão de obra nordestina (Égler, 1961).

A colonização ao longo da EFB, porém, se mostrou infrutífera, pois dos 12.029 colonos introduzidos, apenas 1.802 restaram até 1902, segundo Égler (1961), por problemas de ordem técnica nas práticas agrícolas. Apesar de tudo, a prática da colonização dirigida ao longo da EFB foi fundamental para a estruturação da rede urbana da região bragantina e, por consequência, do Nordeste paraense.

Ao longo de seu trajeto, a EFB possuía 46 pontos, entre estações, paradas e estribos, que correspondem hoje, na sua maioria, a municípios do Nordeste paraense, e que, na época, correspondiam às principais localidades da região. Além disso, a ferrovia ajudou a fortalecer o papel de dois núcleos que serviam de entrepostos comerciais por onde passavam ramais da estrada de ferro: Castanhal e Igarapé-Açu. Por serem "ponta de trilhos", esses núcleos tiveram sua centralidade regional reforçada pela dependência que as outras localidades ao longo dos ramais tinham em relação as mesmas (Égler, 1961 e Ribeiro, 2015).

Nesse contexto da implantação da EFB, no final do século XIX, cabe destacar que Marapanim, desde sua fundação como freguesia (1869) até à sua elevação à categoria de vila (1874) e, depois, cidade (1895), ainda tinha a agricultura como base da sua economia, e a sua população era composta, majoritariamente, por lavradores-pescadores. A comercialização do peixe para exportação era realizada tão somente por meio do peixe salgado ou seco.

A população do município cresceu nesse período, o que também pode indicar um aumento dos consumidores do pescado (Castro, 1998). O contato com outros centros urbanos, principalmente Belém, se fazia pelos rios e pelo mar, através de barco a vapor e canoasgeleiras, que transportavam produtos e pessoas, de modo que a circulação entre esta 
aglomeração humana e outras localidades era demorada e penosa, dificultando, assim, a comercialização do peixe (Furtado, 1987).

Embora Marapanim não tenha sido alcançada materialmente pela via férrea que dinamizava a economia do nordeste paraense desde o final do século XIX, é preciso destacar que a microrregião do Salgado não ficaria imune à sua centralidade, pois, como demonstrou Furtado (1987), foram adotadas diferentes estratégias para alcançar a estrada de ferro e, por meio delas, fazer a produção do litoral chegar a Belém: Uma dessas formas era navegando pelo Rio Marapanim, até atingir a localidade de Cipoal, posteriormente, caminhando $6 \mathrm{~km}$, alcançava-se a parada do trem em Jambuaçu. Outra forma de acesso à ferrovia era se deslocando até a estrada Curuçá-Castanhal ${ }^{5}$. Por fim, podia-se aceder à EFB subindo o Rio Marapanim até a localidade de Matapiquara e daí percorrer $20 \mathrm{~km}$ por terra até ao núcleo de Igarapé-Açu, onde havia uma estação ferroviária (Furtado, 1987).

O terceiro momento desta formação espacial está relacionada com as políticas de modernização implantadas na Amazônia depois dos anos 1950. Tinham como objetivo central promover a integração nacional, do território e do mercado e expandir o modo de produção capitalista em direção às fronteiras de recursos, principalmente, para a Amazônia. A predominância da circulação por estradas de rodagem em substituição da EFB contribuiu para modificações fundamentais na estruturação da rede urbana da zona bragantina e da própria microrregião do Salgado, uma vez que possibilitou a existência de interações de maior amplitude no território, para além da região. Outro processo decorrente foi o surgimento de novos núcleos urbanos próximos as rodovias, o que contribuiu para mudanças na divisão territorial do trabalho. Assim, as cidades de Castanhal e Capanema tiveram as suas centralidades regionais reforçadas a partir da reorganização do espaço regional marcada por esse novo eixo de circulação, pois concentraram o comércio e serviços regionais (Ribeiro, 2015).

Por mais que a implantação da rede rodoviária voltada à integração da Amazônia ao restante do território brasileiro a partir da década de 1950, ressalta-se que no Salgado paraense ela já existia desde o início do século XX, pois a cidade de Marapanim já estava interligada por hidrovias, ferrovia e rodovias (mesmo que precárias) a Belém, através de uma estrada que a conectava com a estrada Curuçá-Castanhal, desde 1936 (Furtado, 1987).

\footnotetext{
${ }^{5}$ Existia desde 1902, mas cujo acesso, a partir de Marapanim, era tortuoso, o que somente foi solucionado em 1938, com a construção de uma "estrada carroçável" ligando Marapanim à estrada Curuçá-Castanhal.
} 
Segundo Furtado (1987), a expansão da rede rodoviária permitiu maior circulação na microrregião do Salgado, impulsionando a distinção de duas áreas no município já percebida na década de 1950. Uma no interior, onde a atividade agrícola era predominante, e outra na costa, especializada na atividade pesqueira. Furtado $(1987,64)$ ainda esclarece que:

Marapanim foi recortado por estradas atrofiaram sua posição como centro catalizador e redistribuidor dos produtos das comunidades circunvizinhas, integrantes de sua jurisdição político-administrativa. A cidade perdeu a sua antiga vida de relação. Deixou de ser o centro religioso, social e comercial. As vilazinhas do interior marapanienses ficaram menos dependente da cidade para realizar transações comerciais.

A cidade de Marapanim perde, portanto, muitas das funções de mediação comercial do município, pois as diversas povoações agora têm contato mais regular com outros centros urbanos regionais que conseguem polarizar e irradiar com mais força as trocas materiais e imateriais, principalmente Belém e Castanhal. A partir dos anos 1930, além das estradas, é possível perceber a presença de algumas inovações tecnológicas no município, como o aumento do uso de redes de pesca pré-fabricadas industrialmente no Sul do Brasil e a introdução do motor nas embarcações, coexistindo com a pesca que remonta ao período provincial do Pará, como a "pesca de curral" ${ }^{6}$ (Furtado, 1987).

Com a consolidação da rede rodoviária na década de 1970, a população marapaniense teve maior contato com outros mercados e os pescadores e marreteiros foram então pressionados a obter o pescado que então fazia parte de uma comercialização mais complexa, de um mercado territorialmente mais amplo e que tinha outros modos de consumo. Ao mesmo tempo, as populações inseridas na economia da pesca tiveram, desde então, maior contato com bens materiais e com um estilo de vida mais urbano, tendo Belém e Castanhal como referências (Santana, 2013 e Furtado, 1987).

No município também se expandiu e se consolidou, a partir da expansão rodoviária, a prática de turismo e da especulação imobiliária (Santana, 2013), salientando-se a produção de segundas residências em algumas localidades, como Marudá (Furtado, 1987) e na cidade de Marapanim, enquanto aumentava o fluxo populacional que movimentava a economia desses espaços em certos períodos do ano, principalmente, nas férias escolares de julho e final de ano. Nesses períodos, na atualidade, o município recebia veranistas que destoavam

\footnotetext{
${ }^{6}$ Grande armadilha fixa, construída com várias peças de madeira (varas e cipós) (Furtado, 1987).
} 
do restante do ano da economia pesqueira, além de alterarem a paisagem e a dinâmica das localidades.

Neste início do século XXI, observa-se no município um aumento de comércios e serviços, como se constata com os indicadores da participação dos serviços no Produto Interno Bruto (PIB) municipal que cresceu $167,8 \%$ em nove anos. Acresce-se que, apesar do setor agropecuário e da indústria terem crescido $99,2 \%$ e $230,9 \%$, respectivamente, no mesmo período, assim mesmo é o setor de serviços que representa $73,4 \%$ do PIB marapaniense em 2011. Entende-se que o comércio e os serviços ocorrem principalmente nos centros urbanos, como é o caso da cidade de Marapanim.

Outro crescimento na cidade relaciona-se com a expansão de sua malha urbana, que no intervalo de, aproximadamente, 30 anos, ou seja, entre 1987 e 2015 (Figura 1) se expandiu nos sentidos Leste e Nordeste em direção à Rodovia PA-318 e ao Igarapé do Seco-Velho. Assim, a cidade de Marapanim cresce em direções contrárias ao local de início do povoamento ${ }^{7}$, expansão que se estende e se dispersa pelo principal centro de comércio e serviços da cidade, a Avenida Barão do Rio Branco; e mais recentemente no eixo da PA-318 em direção oeste (Barbosa, 2017).

Furtado (1987) atribui as mudanças econômicas e socioculturais observadas em Marudá na década de 1980 a dois fatores: a expansão capitalista em áreas rurais e a urbanização. Essas mudanças ocorreram porque, primeiro, os territórios de Marapanim tiveram acesso facilitado às dinâmicas de mercados dos centros urbanos como Belém e Castanhal, que se expandiram no século $\mathrm{XX}$, relaciona-se com o aparecimento de um estilo de vida urbano modernizado.

Marapanim expandiu suas relações para com outros centros urbanos menores, nos quais poderiam comercializar mercadorias e serviços, dilatando as trocas materiais e imateriais entre diversas cidades locais, articulando-as as dinâmicas regionais e nacionais que os territórios marapanienses desigualmente se inseria.

Portanto, o Urbano no município de Marapanim não se manifestou apenas na cidade, mas também em outros aglomerados humanos. Assim, a urbanização transcende os limites da

\footnotetext{
${ }^{7}$ Nas proximidades da Praça das Vitórias, próximo à embocadura do Igarapé do Pagé e à margem oeste do Rio Marapanim.
} 
cidade, alcançando populações do campo, embora tendo a cidade como sua referência espacial. Ainda assim, o Rural persistiu nestas aglomerações e na própria cidade de Marapanim, pois a submissão ao tempo da natureza, característico da agricultura e pesca marapaniense, denuncia esse aspecto rural. Existe, pois, nesta cidade, uma relação dialética entre o urbano e o rural (Barbosa, 2017).

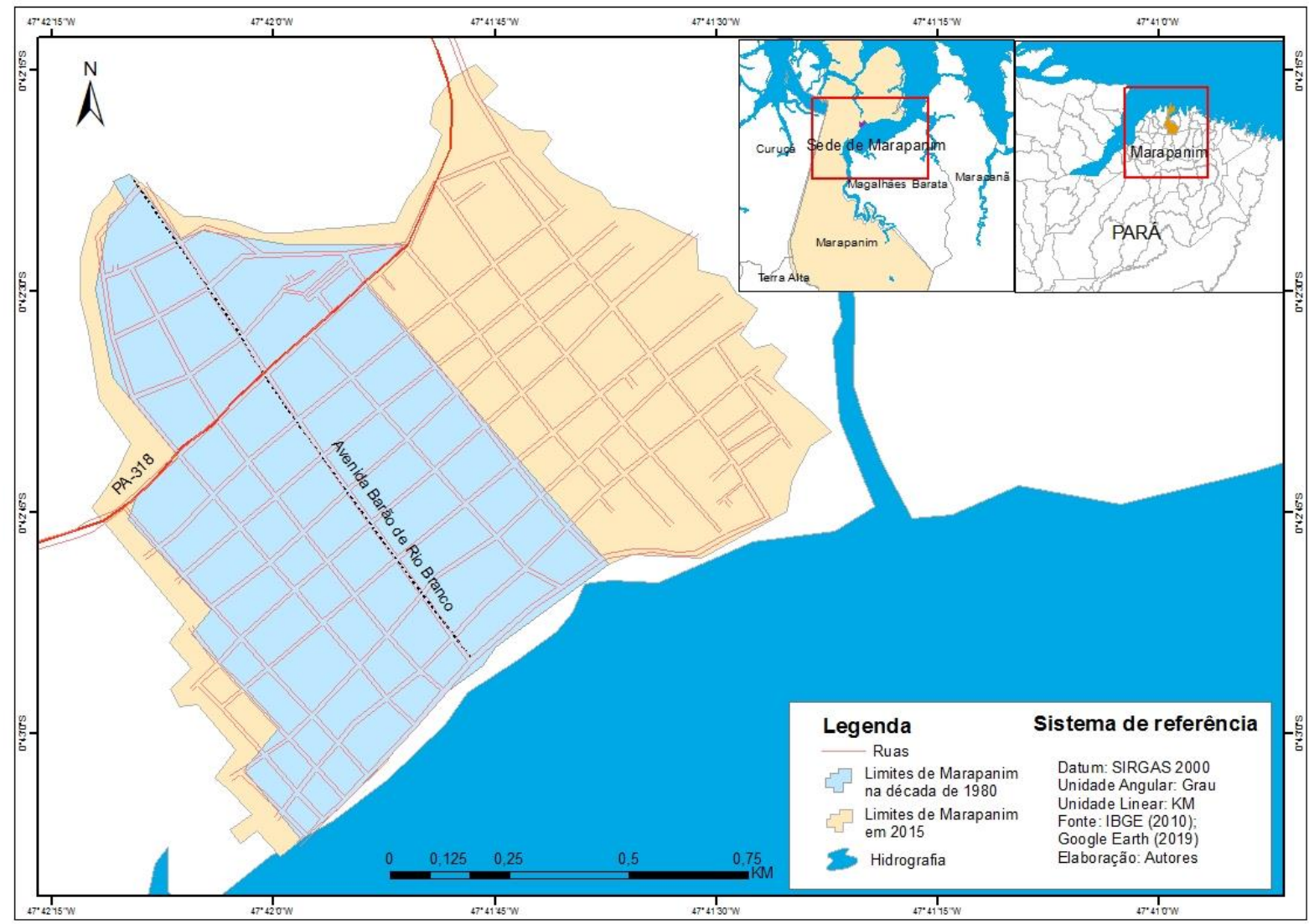

Figura 1 - Carta-imagem da expansão da cidade de Marapanim entre 1987 e 2015 Fonte: IBGE (2010) e trabalho de campo. Elaboração dos autores, 2020.

\section{A pequena cidade de Marapanim nas redes da pesca}

Diante da explanação sobre a formação territorial do Salgado paraense e de Marapanim, registrou-se o avanço da modernização do território, sendo que Marapanim, ainda que enquanto cidade periférica e desigualmente inserida, no momento, passa a se articular mais fortemente com outras cidades, sejam elas pequenas, médias ou a própria metrópole de Belém. 
Enquanto cidade local, Marapanim concentra funcionalidades políticas, comerciais e de serviços, exercendo uma responsabilidade para com outras localidades, vilas, moradores do campo e dos interiores, principalmente os imediatamente próximos. Durante o processo de pesquisa foi possível identificar que a produção do pescado tem ocorrido durante longo período no município, e que a concentração da sua comercialização na cidade de Marapanim foi fundante de uma especialização da própria produção de seu espaço.

Procura-se, pois, compreender a divisão territorial do trabalho na cidade de Marapanim, salientando, pela relevância, a produção do pescado (incluindo a sua comercialização, circulação e consumo), espacializando os seus circuitos e o estabelecimento das suas redes. Elencam-se, a partir da atividade pesqueira, quatro momentos para compreender o que estamos chamando de "as redes da pesca da cidade de Marapanim": obtenção e/ou produção de materiais para a pesca; a pesca; a comercialização e o consumo; e, por fim, a organização desta pequena cidade para a atividade pesqueira.

\subsection{Obtenção e/ou produção de materiais para a pesca}

Designam-se materiais para a pesca os objetos necessários para a prática pesqueira, identificou-se basicamente cinco no lócus de pesquisa: os alimentos, as embarcações, o combustível, o gelo e os artigos de pesca.

O acesso aos alimentos por parte dos pescadores da cidade pode ocorrer através da compra em estabelecimentos comerciais locais, ainda, pela doação ou retribuições futuras de algum indivíduo próximo (vizinho, parente, amigo etc.). Há casos em que agentes intermediários ${ }^{8}$ fornecem um crédito ${ }^{9}$ em dinheiro (chamado de vale), que possibilita o acesso do pescador a alimentos. A obtenção de combustível e de gelo é semelhante ao que ocorre com os alimentos $^{10}$.

8 Tais agentes podem ser classificados em patrão aviador, atravessadores e marreteiros. 0 patrão aviador financia a pescaria, custeia a alimentação, o combustível e o gelo necessário, e toda a produção é dirigida obrigatoriamente a ele, que geralmente é o dono da embarcação. Sobre o atravessador e o marreteiro, ver nota 3.

90 Sistema de Aviamento consiste no fornecimento de crédito, na forma de dinheiro ou mercadoria, ao produtor, que fica comprometido a destinar sua produção ao fornecedor, tanto para quitar a dívida contraída com o crédito quanto por conta de relações clientelistas. Essa relação de aviamento, na Amazônia, possui várias faces e foi impulsionada principalmente no fim do século XIX e início do XX com o surto econômico advindo com o extrativismo do látex na Amazônia (Gonçalves, 2015).

10 Informação cedida por Raimundo Cordovil Favacho ("Mundinho"), marreteiro e diretor do Mercado Municipal na cidade de Marapanim, no dia 23 de junho de 2017. 
Também é possível adquirir por empréstimo, escambo, aluguel ou por aquisição as embarcações na cidade de Marapanim, pois existem carpinteiros navais que respondem às solicitações dos pescadores da cidade e de outras localidades dentro e fora do município ${ }^{11}$. O acesso à embarcação pelo pescador, majoritariamente, é efetuado através da compra ou pelo uso da embarcação de um outro indivíduo, pescador ou agente intermediário, que fica com uma parte do que for pescado.

Quanto aos artigos de pesca, eles são oferecidos na cidade em estabelecimentos varejistas que vendem diversas mercadorias para pesca, como motores, rabetas ${ }^{12}$, redes malhadeiras, cordas plásticas, chumbo, panagens, isopores e anzóis. Assim, os pescadores da cidade obtêm esses materiais na própria cidade (tendo um menor dispêndio comparado), que atende às necessidades de pescadores de outros povoados próximos, como as vilas pesqueiras de Camará, Araticum-Miri, Vista Alegre, Tamaruteua e Marudá. Estas relações reforçam a convergência exercida pela cidade de Marapanim.

A oferta de artigos de pesca na cidade de Marapanim revelou relações mais abrangentes, pois a obtenção dos produtos pelos estabelecimentos comerciais está conectada com as cidades de São Paulo (SP), Diadema (SP), Curitiba (PR), Belém (PA), Castanhal (PA) e Capanema (PA), estabelecendo redes nacionais (Sul e Sudeste do Brasil) e regionais (Nordeste paraense). Paralelamente, surgem redes imateriais, um circuito de cooperação espacial (Silveira, 2011) representado por trocas pela internet (via e-mail), telefone e pelo sistema bancário.

Essas informações explicitam as relações entre o circuito inferior e o circuito superior da economia ${ }^{13}$ (Santos, 1979), pois o comércio varejista que abastece a cidade e as povoações

\footnotetext{
${ }^{11}$ Informação cedida por Raimundo Torres dos Santos, pescador do Porto da Pedra na cidade de Marapanim, em 20 de junho de 2017.

${ }^{12}$ Canoa ou pequena embarcação com motor com hélice (removível) na popa. Trata-se de um meio de transporte muito utilizado pelo pequeno pescador, tanto para pesca, quanto para a circulação em geral.

${ }^{13}$ Ambos os circuitos da economia urbana são resultantes da modernização, porém o circuito superior é resultado direto e compõem as atividades criadas para servirem ao progresso tecnológico e a população que dele se beneficia, e, assim, se refere aos negócios bancários, comércio de exportação e indústria de exportação, indústria urbana moderna, comércio moderno, serviços modernos, comércio atacadista e transporte. O circuito inferior é resultado indireto da modernização e parcialmente os indivíduos se beneficiam, ou não se beneficiam, do progresso técnico e suas vantagens, compondo as atividades de fabricação de capital não intensivo, por serviços não modernos, geralmente abastecidos pelo nível de venda a varejo e pelo comércio em pequena escala e não moderno (Santos, 1979).
} 
circunvizinhas municipais, com relações próximas com seus clientes, estabelecem transações comerciais com empresas industriais, modernas e multinacionais.

É importante ressaltar também que parte da produção dos materiais para a pesca é produzida pelos próprios pescadores de modo artesanal, como aponta Furtado (1987), sejam por redeiros, que tecem as suas próprias redes de forma individual, ou por curralistas, que trabalham coletivamente em forma de mutirões para construir os currais, uma grande armadilha fixa com várias peças de madeira (varas e cipós) ${ }^{14}$.

\subsection{A pesca}

A cidade de Marapanim é um espaço de extrativismo do pescado em que é possível observar a captura de peixes de água doce e de água salgada. Este pescado é desembarcado em vários portos que rodeiam a cidade, ao longo das margens dos Rios Marapanim e Cajutuba e dos Igarapés ${ }^{15}$ do Seco-Velho e Pagé.

As espécies de peixes são capturadas de acordo com a época do ano (Santos et al., 2005), pois a presença de determinados cardumes está diretamente relacionada com o regime anual das águas dos rios da região ${ }^{16}$. Além desse regime anual, a pesca também acompanha a dinâmica diária das marés, já que, a partir de determinado período do dia, há ou não

\footnotetext{
${ }^{14}$ Curralistas e redeiros são termos aplicados ao pescador independentemente de ele deter a propriedade do equipamento de pesca - curral ou rede. A distinção se dá fundamentalmente em função do predomínio do tipo de equipamento de pesca utilizado pelos mesmos: curral para o curralista e rede para o redeiro (Futado, 1987).

${ }^{15} \mathrm{O}$ termo significa na linguagem regional ou indígena, caminho de canoa pequena. Trata-se de um pequeno curso d'água entre duas ilhas ou entre uma ilha e a terra-firme. Em geral, é utilizado para prática da pesca com uso de linha e anzol, para circulação entre as residências da comunidade ou para tomar banho.

${ }^{16}$ No inverno amazônico, ou época de enchente, aproximadamente entre os meses de dezembro a junho, o Rio Amazonas apresenta maior volume e descarga de água no Oceano Atlântico (em torno de $240.000 \mathrm{~m}^{3}$ por segundo), fazendo com que as águas doces do rio afastem as águas salgadas do oceano na costa paraense, nessas imediações, as águas do litoral ficam menos salgadas ou salobras e, assim, os peixes habitantes das águas salgadas do oceano procuram correntes mais afastadas do litoral. Já no verão amazônico, ou época de vazante, aproximadamente entre os meses de julho a novembro, o volume de descarga do Rio Amazonas diminui (em torno de $207.000 \mathrm{~m}^{3}$ por segundo) no Oceano Atlântico, resultando em maior presença de água salgada e peixes de águas oceânicas na costa (Furtado, 1987). O regime das águas do Rio Amazonas afeta a costa do município marapaniense e do Rio Marapanim, pois no período chuvoso/enchente, o limite do alcance da maré salina nesse rio é por volta de $42 \mathrm{~km}$, já no período de estiagem/vazante, o alcance chega a cerca de $62 \mathrm{~km}$ (Prost et al., 2013). No período de enchente do Rio Marapanim, suas águas doces empurram as águas salgadas do oceano, que não conseguem avançar para o interior do continente, já no período de vazante, a água doce perde volume e permite o avanço da água salgada. As águas doce e salgada apresentam, cada uma, espécies de peixes particulares e, então, os regimes das águas regionais influem na disponibilidade e diversidade de peixes na microrregião do Salgado.
} 
disponibilidade de peixes em um determinado local e a possibilidade de deslocamento até este local.

A sazonalidade das espécies pesqueiras também influi no trabalho e na produção, pois os instrumentos de trabalho possuem atributos de acordo com as intenções dos pescadores e das espécies de interesse, já que, para cada espécie, há uma forma particular de captura (Alves et al., 2015). Em síntese, se por um lado há uma influência das condições da natureza, por outro existe a pressão do mercado, das condições tecnológicas e sociais para a dinâmica da pesca, como esclarece Furtado (1987).

\subsection{A comercialização e o consumo}

É possível afirmar que a maior parte do pescado capturado pelos pescadores da cidade de Marapanim é comercializado na própria cidade e, como foi referido a produção e o consumo é intermediada pelos marreteiros/atravessadores que se articulam em diferentes escalas.

Segundo os dados de Alves et al. (2015), os pescadores do Porto do Bugário, o principal porto na cidade de Marapanim, vendem, majoritariamente, para os marreteiros ou atravessadores, destinando apenas $6 \%$ dos seus produtos para os consumidores. Essa realidade pode ser encontrada nos restantes dos portos.

O lucro da comercialização é geralmente usado para a compra de outras mercadorias, tanto para consumo, quanto para o trabalho de pescaria. Devido à baixa renda dos pescadores (87\% deles possuem uma renda familiar mensal inferior ou igual a 1 salário-mínimo), há uma dificuldade de capital e estabilização financeira que dê acesso aos produtos de consumo e aos instrumentos de trabalho, como apontam Alves et al. (2015) e alguns pescadores ${ }^{17}$.

Se por um lado, têm-se os agentes intermediários da cidade de Marapanim que adquirem o pescado na própria cidade e em outras localidades do município, como nas vilas pesqueiras de Marudá, Vista Alegre, Camará e Tamaruteua, por outro lado há os intermediários que compram em outros municípios costeiros do Pará, a exemplo de Curuçá e suas localidades

17 Informações cedidas por Napoleão da Costa Freitas e Manoel Salomão Moreira Barata, pescadores do Porto do Bugário na cidade de Marapanim, em 22 de junho de 2017. 
(Araquaim e Abade), Vigia, Salinópolis (localidade de Cuinarana), São João de Pirabas e até de Belém ${ }^{18}$. Deste modo, a compra do pescado feita pelos marreteiros da cidade de Marapanim pode ter alcance na microrregião do Salgado e na Região Metropolitana de Belém (RMB).

As vendas efetuadas pelos agentes intermediários são, por seu turno, majoritariamente efetuadas na própria cidade, porém de duas formas: para estabelecimentos que vendem o pescado para consumidores da própria cidade (à vista, a prazo, a crédito, no "fiado"19, escambo ou ainda pela troca do pescado por futuro trabalho); outra forma de venda é para intermediários que levam o pescado para as cidades de Castanhal e Belém. Esse último tipo de venda intensifica-se quando a produção pesqueira da cidade é expressiva.

Quando a produção é elevada, os portos da cidade de Marapanim, principalmente o Bugário, além do Mercado Municipal, abastecem caminhões frigoríficos de supermercados, que também adquirem pescados nas vilas pesqueiras de Camará e Vista Alegre, por exemplo.

Na pequena cidade de Marapanim, as relações comerciais da atividade pesqueira dão-se por um circuito inferior da economia (Santos, 1979), as relações econômicas entre pescadores e agentes intermediários são de baixo volume, com pouca possibilidade de capitalização. Outro fator que contribui para a baixa capitalização são os modos não capitalizados de produção, trocas permeadas por solidariedades, como as doações de materiais para pesca entre pescadores ou quando o pescador reparte a "boia" (quantidade de alimento limitada a uma ou algumas refeições) entre os vizinhos e conhecidos, que fazem o mesmo em outras oportunidades, seja com peixe ou com outros produtos ${ }^{20}$.

Ao mesmo tempo, tais relações são captadas pelo circuito superior da economia, pois diante da compra do pescado não constam as solidariedades do reino da práxis e os trabalhos não remunerados, podendo haver hipervaloração (ocorrência rara). A desvalorização do trabalho, porém, são mais comum, por não serem os produtores do pescado a controlar o

18 Informações cedidas por Raimundo da Silva Barroso ("seu Barroso") e Manoel Barata Rodrigues ("Barata"), que são marreteiros locais e Raimundo Cordovil Favacho (“Mundinho"), marreteiro e diretor do Mercado Municipal, no dia 23 de junho de 2017.

${ }^{19}$ É a compra de produtos com prazo (in)determinado para pagar geralmente sem juros e baseado em relações solidárias entre vendedor e comprador.

${ }^{20}$ Informação cedida por Raimundo Torres dos Santos, pescador do Porto da Pedra, em 20 de junho de 2017. 
preço (oferta e procura), influenciado pelo valor imposto pelos intermediários externos à cidade (Santos, 1979).

\subsection{A organização da pequena cidade de Marapanim para a atividade pesqueira}

Na cidade de Marapanim existem espaços que estão diretamente envolvidos com as redes da pesca artesanal, como os estaleiros, os portos, os estabelecimentos de materiais para a pesca, as peixarias, o Mercado Municipal, a sede da Colônia dos Pescadores Z-6, o Posto Fiscal, as casas que vendem combustível e a fábrica de gelo (Figura 2).

Destacam-se, porém, os portos os principais espaços de desembarque do pescado e da transação comercial entre os pescadores e os agentes intermediários. Contudo, os mesmos possuem pouca infraestrutura moderna e a produção desses espaços foram, sobretudo, da responsabilidade dos pescadores. Localizam-se nas margens dos principais corpos d'água da cidade, interligando a sede do município com os territórios circunvizinhos, tanto os de água doce quanto os de água salgada.

Os principais portos da cidade de Marapanim são, todavia, mais do que espaços de troca de mercadorias, pois são também locais de encontro e sociabilidade entre os pescadores e outros habitantes. Aqui, usam esses lugares para o lazer, para o trabalho, para a alimentação advinda da pescaria e/ou de suas casas, para o consumo de bebidas alcoólicas, aos fumos, às relações políticas e culturais e à contemplação da paisagem. 


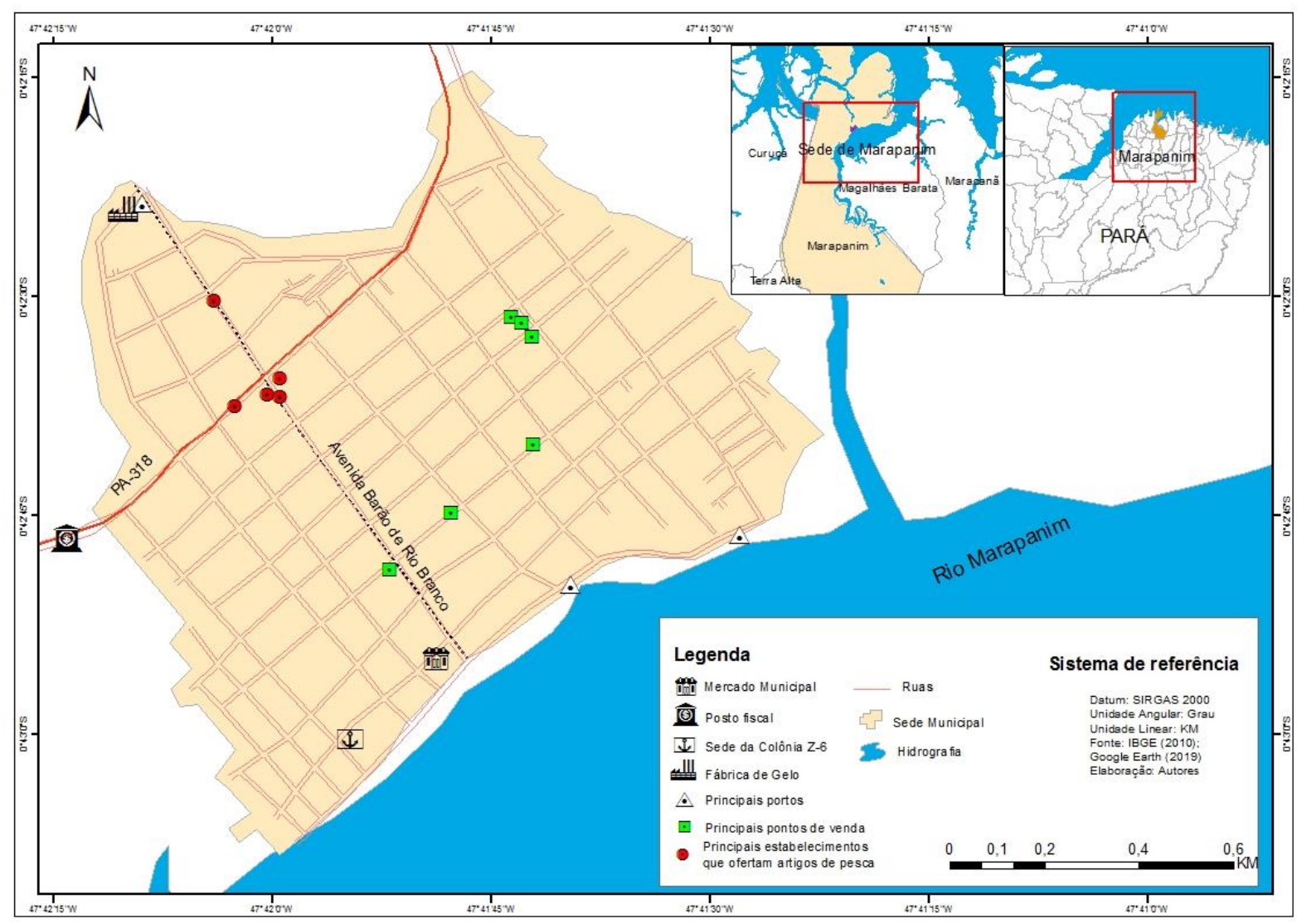

Figura 2 - Carta-Imagem dos pontos ligados à pesca na cidade de Marapanim. Fonte: IBGE (2010) e trabalho de campo. Elaboração dos Autores, 2020.

Os mais importantes estabelecimentos comerciais que disponibilizam materiais para pesca localizam-se nas proximidades da Rodovia PA-318, que interliga a sede de Marapanim com o território de água salgada (ao Norte) mas também com o território de água doce e os centros urbanos regionais e nacionais (ao Oeste e ao Sul). Do mesmo modo, estão próximos da Av. Barão do Rio Branco onde, entre a Rua Diniz Botelho e a PA-318, localiza-se o centro comercial da cidade, que dispõe de produtos para a população: alimento, vestuário, produtos agrícolas, construção civil, materiais de pesca, para além da concentração de serviços.

Os principais espaços de comercialização do pescado podem ser divididos entre os pontos fixos e os pontos móveis de venda. Dentre os fixos, estão o Mercado Municipal e as peixarias, que são parte das casas dos agentes intermediários locais ${ }^{21}$, enquanto os pontos móveis de venda podem ser observados em algumas ruas ao longo da cidade, onde

\footnotetext{
${ }^{21}$ As principais peixarias localizam-se, sobretudo, na Rua Tenente Saraiva entre as ruas Anísio Oeiras e Bartolomeu Ferreira, e na Rua Anísio Oeiras, entre a Av. Barão do Rio Branco e a Rua Tenente Saraiva, mais recentemente se localizam na Rodovia PA-318, distantes do Mercado Municipal (Figura 2).
} 
marreteiros e/ou pescadores carregam os isopores com gelo e o pescado em carros de mão, motos ou carros. Há, contudo, uma concentração desses comerciantes na Rua Anísio Oeiras, no trecho entre a Av. Barão do Rio Branco e a Rua Tenente Saraiva, vendendo-se o pescado nas esquinas dessa rua. São espaços de sociabilidade entre pescadores, agentes intermediários e consumidores locais, que dinamizam esses locais, sobretudo, na parte da manhã entre as segundas-feiras e as sextas-feiras.

Outros locais diretamente ligados à atividade pesqueira são a sede da Colônia de Pescadores Z-6, tendo como principal função orientar e apoiar os pescadores em relação ao acesso à previdência, mas que enfrenta dificuldade em articular os pescadores. Pontuam também o Posto Fiscal, que se localiza próximo da entrada da cidade, que servem para controlar e fiscalizar a entrada e saída do pescado.

\section{CONSIDERAÇÕES FINAIS}

O estudo da inserção de uma pequena cidade do Salgado paraense na divisão territorial do trabalho, a partir de sua economia pesqueira artesanal, permite compreender uma economia política da urbanização e economia política da cidade (Santos, 2009) que, não só revelam relações comerciais, mas também de solidariedade.

Pode-se afirmar que Marapanim passou a se constituir como parte da divisão territorial do trabalho, exercendo uma função hierárquica de dispersão do comércio e da produção, para além de inserir sua produção no comércio microrregional, regional, e mesmo nacional e mundial. Logo, o pescado transforma-se em mercadoria, algo já apontado por Loureiro (1985, 183), em trabalho sobre a pesca em Vigia (PA). Ressalta-se que, embora não deva desconsiderar a exploração do trabalho, é por meio da comercialização que se dá a realização do pescado enquanto mercadoria, cujo preço deve comportar a remuneração dos diferentes agentes envolvidos no processo.

Todavia nem todas as remunerações têm um valor estabelecido, e o controle do valor não é, majoritariamente, feito pelo pescador. Aqui é interessante perceber a dupla temporalidade de tais processos, visto que, tanto no Salgado quanto em Marapanim, permanecem relações de solidariedade em que o pescado não é necessariamente mercadoria. 
Registra-se, ainda, que parte desse trabalho solidário é fundamental para a reprodução da vida, mas que não deixa de ser captado pelo mercado que o insere em sua reprodução enquanto relações não capitalistas e trabalho não remunerado, o que possibilita um maior lucro e/ou a diminuição do valor do pescado (Martins, 1996).

A formação territorial do Salgado, assim como a atividade da pesca e a divisão territorial do trabalho da pequena cidade de Marapanim, permite fazer comparações com as formulações teórico-metodológicas de Oliveira (2009) e Trindade Jr. (2013) e assinalar, por proposição, avanços no que diz respeito às tipologias de pequenas cidades na/da Amazônia.

O primeiro apontamento condiz com a possibilidade de analisar uma área - no caso, a microrregião do Salgado - que estava em constante relação de produção e comercialização com centros urbanos via deslocamentos pelos rios e pelo mar, através de pequenas embarcações, mas também com a presença de transporte por grandes navios (São LuísBelém) e, ainda, articulando-se com a ferrovia regional no final do século XIX.

Com o estabelecimento da rede rodoviária, iniciada no começo do século XX, de iniciativa estadual e municipal, ou seja, antes das iniciativas do governo federal a partir da década de 1950 na Amazônia, destoa-se, de certa maneira, com o padrão histórico explicativo que aponta um novo modelo de circulação na região, mas apenas a partir dos anos 1960, que priorizou a estrada, "substituindo" o hidroviário.

Outro pontoa salientar a possibilidade de estudo em uma área onde existam influências da sazonalidade do pescado e que implica em uma variação na direção e intensidade das redes que envolvem a economia pesqueira. Nesse sentido, a cidade de Marapanim muda sazonalmente segundo a disponibilidade de peixes de água doce (inverno) e de água salgada (verão), influenciando mudanças referentes a economia, a política, a expressões culturais e até à paisagem desse espaço. Destaca-se que tal sazonalidade não determina totalmente as dinâmicas da cidade, embora seja possível descobrir mudanças nos regimes de trabalho, da pesca, da agricultura (plantios entre dezembro e janeiro) (Furtado, 1987) e do extrativismo (período da safra de determinadas frutas). Nesse sentido, enfatiza-se a importância das relações campo e cidade.

Por último, levanta-se a hipótese de uma tipologia específica para as pequenas cidades do Salgado na sequência da colonização antiga do litoral, com influência jesuíta, que deu 
conformidade aos aldeamentos indígenas dispersos. Seguiu-se uma desorganização estatal do controle e distribuição da terra e da produção no período pombalino; subsequentemente houve a distribuição para a produção agrícola no período da borracha, o que manteve uma relativa quantidade de pequenas comunidades ao longo do rio; e, posteriormente, ao longo das estradas, onde há convergência às pequenas cidades, como para a cidade de Marapanim, com sua influência zonal imediata e que se constitui em uma rede local. Por outro lado, conecta-se com redes regionais, nacionais e mundiais (Santos, 2014), reforçando sua importância hierárquica.

Nesse sentido, os territórios do município de Marapanim não estão isolados do fenômeno urbano que ocorre na região amazônica e no Brasil, apesar de tal dinâmica não se manifestar como geralmente acontece noutras realidades metropolitanas, de cidades médias e pequenas, ou mesmo totalmente de acordo com as tipologias antes propaladas. Por ser de colonização antiga em área litorânea e de rio, para além das prolongadas relações entre populações tradicionais e modernas. Em paralelo, identifica-se que não há um movimento de extinção das ruralidades em Marapanim, pelo contrário, é possível inferir que existe uma relação dialética entre urbano e rural.

\section{Referências Bibliográficas}

Almeida, A. W. B. de. Biologismos, geografismos e dualismos: notas para uma leitura crítica de esquemas interpretativos da Amazônia que dominam a vida intelectual. In A. W. B. de Almeida. Antropologia dos Archivos da Amazônia. Rio de Janeiro: Casa 8/FUA, 2008.

Alves, R. J. M. et al. Caracterização socioeconômica e produtiva da pesca artesanal no município de Marapanim, Pará, Brasil. Observatorio de la economia latinoamericana, Málaga, 2015.

BAENA, M. B. M. Informações sobre as comarcas da Província do Pará. Organizadas em virtude do aviso circular do Ministério da Justiça de 20/09/1883. Pará, Typographia de Francisco Costa Júnior, 1885.

BARBOSA, L. M. O urbano no litoral de rias paraense: a pequena cidade de Marapanim nas redes da pesca. Trabalho de Conclusão de Curso (Bacharelado e Licenciatura em Geografia) - Universidade Federal do Pará, Belém, 2017.

Borcem, E. R. et al. A atividade pesqueira no município de Marapanim - Pará, Brasil. Revista de Ciências Agrárias, Belém, v. 54, n. 3. p. 189-201, 2011.

Castro, J. A. Noções da história de Marapanim. Belém: Gráfica e Editora Sagrada Família, 1998.

CIDADE-BRASIL. Microrregião do Salgado paraense. Disponível em: <http://www.cidadebrasil.com.br/microrregiao-de-salgado.html>. Acesso em: 25 jul. 2017.

Corrêa, R. L. Estudos sobre a rede urbana. Rio de Janeiro: Bertrand Brasil, 2006.

Damiani, A. L. Cidades médias e pequenas no processo de globalização, Apontamentos bibliográficos In A. L. Damiani; M. Arroyo; M. L. Silveira (orgs.). América Latina: cidade, campo e turismo. São Paulo: Consejo Latinoamericano de Ciencias Sociales (CLACSO), p. 135- 146, 2006. 
Demazière, C. Le traitement des petites et moyennes villes par les études urbaines. Revue espaces et societes, n. 168-169, p. 17-32, 2017.

Égler, E. G. A zona Bragantina no estado do Pará. Revista Brasileira de Geografia, v. 23, n. 3, p. 527-555, 1961.

Endlich, Â. M. Formação socioespacial da região noroeste do Paraná e as pequenas cidades. Boletim de Geografia, n. 25, v. 1, p. 37-58, 2007.

Furtado, L. G. Curralistas e redeiros de Marudá: pescadores do litoral do Pará. Belém: Museu Paraense Emílio Goeldi, 1987.

Gonçalves, C. W. P. Amazônia, amazônias. 3. ed. São Paulo: Contexto, 2015.

Guerra, A. T.; Guerra, A. J. T. Novo dicionário geológico-geomorfológico. 6. ed. Rio de Janeiro: Bertrand Brasil, 2008.

Loureiro, V. R. Os parceiros do mar: Natureza e conflito social na pesca da Amazônia. Belém: Museu Emílio Goeldi, 1985.

Martins, J. S. O tempo da fronteira: Retorno a controvérsia sobre o tempo histórico da frente de expansão e da frente pioneira. Tempo Social - Rev. Sociológica USP, São Paulo, p. 25-70, 1996.

Oliveira, J. A. et al. Cidades, Rede Urbana e Desenvolvimento na Amazônia dos Grandes Rios. In S. Trindade Jr; G. Carvalho; A. Moura; J. G. Neto. (orgs.). Pequenas e Médias cidades na Amazônia. Belém: Federação de Órgãos para Assistência Social e Educacional/ FASE; Instituto de Ciências Sociais Aplicadas/UFPA; Observatório COMOVA, p. 35-57, 2009.

Oliveira, J. A; Schor, T. Reflexões metodológicas sobre o estudo da rede urbana no Amazonas e perspectivas para a análise das cidades na Amazônia brasileira. ACTA Geográfica, Boa Vista, p. 15-29, 2011.

Prost, M. T. et al. Manguezais e estuários da Costa paraense: exemplo de estudo multidisciplinar integrado (Marapanim e São Caetano de Odivelas). In M. T. Prost; A. C. Mendes (org.). Ecossistemas costeiros: impactos e gestão ambiental. 2. ed. Belém: Museu Paraense Emílio Goeldi, p. 73-88, 2013.

Ribeiro, A. C. T. Sentidos da urbanização: desafios do presente. In E. S. Sposito; M. E. B. Sposito; O. Sobarzo. Cidades Médias: produção do espaço urbano e regional. São Paulo: Expressão Popular, 2006.

Ribeiro, W. O. Redes, interações e papéis dos centros urbanos da região nordeste do Pará, Brasil. Anais ENANPUR, v. 16, n. 1, 2015.

Santana, G. Formas organizativas e estratégias de vida no litoral paraense. In M. Prost; A. C. Mendes, (orgs.). Ecossistemas costeiros: impactos e gestão ambiental. 2. ed. Belém: Museu Paraense Emílio Goeldi, p. 175-180, 2013.

Santos, M. A. S. et al. Análise socioeconômica da pesca artesanal no Nordeste Paraense. In XLIII Congresso da Sober: Instituições, Eficiência, Gestão e Contratos no Sistema Agroindustrial, Ribeirão Preto: Sociedade Brasileira de Economia e Sociologia Rural, 2005.

Santos, M. Espaço e sociedade: ensaios. Petrópolis: Vozes, 1979.

Santos, M.. O Espaço Dividido: os dois circuitos da economia urbana dos países subdesenvolvidos. São Paulo: Edusp, 2005.

Santos, M.. Por uma economia política da cidade. In M. Santos. Por uma economia política da cidade. 2. ed. São Paulo: Editora da Universidade de São Paulo, 2009.

Silveira, M. L. O Brasil: território e sociedade no início do século 21 - A história de um livro. ACTA Geográfica, Boa Vista, p. 151-163, 2011.

Sposito, M. E. B. Perspectivas analíticas. In M. E. B. Sposito. O chão em pedaços: urbanização, economia e cidades no Estado de São Paulo. Tese (Livre Docência) - Universidade Estadual Paulista, Faculdade de Ciências e Tecnologia, Presidente Prudente, 2004.

Sposito, M. E. B. Para pensar as pequenas e médias cidades brasileiras. Belém: Federação de Órgãos para Assistência Social e Educacional; Instituto de Ciências Sociais Aplicadas/UFPA; Observatório COMOVA, 2009. 
Sposito, E. S; Jurado Da Silva, P. F. Cidades Pequenas: Perspectivas Teóricas e Transformações Socioespaciais. Jundiaí (SP): Paco Editorial, 2013.

Trindade JR, S. C. Das “cidades na floresta” às "cidades da floresta": espaço, ambiente e Urbanodiversidade na Amazônia brasileira. Papers do NAEA, Belém, n. 321, p. 1-22, 2013.

Trindade JR., S. C. Diferenciação territorial e urbanodiversidade: elementos para pensar uma agenda urbana em nível nacional. Cidades, Presidente Prudente, v. 7, n. 12, p. 227-255, 2010. 